\section{The authors respond to: letters by Catherine Clelland and Shelley Ross}

Dr. Ross ${ }^{1}$ writes that, overall, the Full-Service Family Practice Incentive Program (FSFPIP) has resulted in substantial cost avoidance and reductions in hospital admissions. This is based on cross-sectional comparisons of patients with diabetes, congestive heart failure, chronic obstructive pulmonary disease and hypertension who did and did not receive incentive-based care. The article she cites found that, after adjusting for measurable confounders, patients who had incentives had lower costs for three of the four conditions and had fewer admissions to hospital for all four. ${ }^{2}$

Interpreting differences in costs and admissions to hospital as evidence of cost avoidance and reductions in hospital admissions confuses correlation with causation. We observed that patients with incentives had lower costs and hospital admissions on average, as well as higher continuity or "stickiness," 3 but this was true even before incentives were billed, so this difference cannot be causally attributed to the incentive payments. We previously examined changes in primary care over the full period of investment in the FSFPIP and observed sustained decreases in continuity, although this was across the whole population and not just among patients targeted by FSFPIP. 4

Our article ${ }^{3}$ focused on the complex care incentive because management of complex disease is a critical challenge facing our system, ${ }^{5}$ and most existing research focuses on incentive payments for individual diseases. Given a much higher value ( $\$ 315$ v. $\$ 50-\$ 125$ for chronic disease management), this program costs more than all of the other chronic disease management incentives combined, ${ }^{6}$ and a larger impact was plausible.
Dr. Clelland ${ }^{7}$ suggests that we do not observe effects because earlier chronic disease management incentives had already improved continuity of care. Given methodological limitations of the analyses she cites, we are not convinced this is the case. Even if continuity had increased previously for some patients, it does not alter our conclusion that the more expensive complex care payments did not yield measurable improvements in the outcomes examined.

It was not our objective to examine the impact of the FSFPIP on physician supply, but as both Dr. Ross ${ }^{1}$ and Dr. Clelland ${ }^{7}$ write that the program attracted medical students to family medicine, we wish to offer some additional data relevant to this point. Similar to what was observed in British Columbia, the percentage of Canadian medical graduates choosing family medicine as their first choice for residency climbed from $25.0 \%$ in 2003 to $38.5 \%$ in 2015 across Canada. ${ }^{8}$ Since 2003, the number of family medicine physicians per capita increased by $11 \%$ in BC and by $19 \%$ across Canada. ${ }^{9}$ Over this period, the University of British Columbia's Faculty of Medicine dramatically expanded training capacity, and, between 2003 and 2008, the number of graduates entering family practice more than doubled. ${ }^{10}$ Growth in family medicine is not unique to $B C$, and FSFPIP is not the only policy that might plausibly have shaped observed changes.

\section{Ruth Lavergne PhD}

Assistant Professor, Simon Fraser University, Burnaby, BC

\section{Michael R. Law PhD}

University of British Columbia, Vancouver, BC

\section{Jeremiah Hurley PhD}

Department of Economics, McMaster University, Hamilton, Ont.

\section{Kimberlyn McGrail PhD}

University of British Columbia, Vancouver, BC

Cite as: CMAJ 2017 February 13;189:E251. doi: $10.1503 / \mathrm{cmaj} .732524$

\section{References}

1. Ross S. Incentive funding in BC is a key factor for physicians to remain in family practice [letter]. CMAJ 2017;189:E249. DOI:10.1503/ cmaj. 732478 .

2. Hollander MJ, Kadlec H. Incentive-based primary care: cost and utilization analysis. Perm J 2015; 19:46-56.

3. Lavergne MR, Law MR, Peterson S, et al. A population-based analysis of incentive payments to primary care physicians for the care of patients with complex disease. CMAJ 2016; 188:E375-83.

4. Lavergne MR, Peterson S, Mckendry R, et al. Fullservice family practice in British Columbia: policy interventions and trends in practice, 19912010. Healthc Policy 2014;9:32-47.

5. Schoen C, Osborn R, Squires DA, et al. New 2011 survey of patients with complex care needs in eleven countries finds that care is often poorly coordinated. Health Aff (Millwood) 2011;30: 2437-48.

6. Health Sector Information Analysis and Reporting Division. MSP Fee-For-Service (FFS) Payment Analysis 2010/2011-2014/2015. BC Ministry of Health; 2015.

7. Clelland CA. General Practice Services Committee incentives are drivers in enticing medical students to choose family medicine [letter]. CMAJ 2017;189:E250. DOI:10.1503/cmaj. 732457.

8. 2016 R-1 match - first iteration chart 11: top three CMG discipline choices (1994-2016). Ottawa: Canadian Resident Matching Service; 2016. Available: www.carms.ca/wp- content/ uploads/2016/08/Chart_11_Top_three_CMG_ discipline_choices_1994- 2016.pdf (accessed 2016 Nov. 14).

9. Supply, distribution and migration of Canadian physicians (SDMP) Table 23.1 Ottawa: Canadian Institute for Health Information; 2015. Available: https://secure.cihi.ca/estore/productFamily.htm ?pf=PFC3269???=en\&media=0 (accessed 2016 Nov 14).

10. Evaluation Studies Unit. Long-term outcomes evaluation executive summary 2012-13, UBC's contribution to physician supply in the province. Vancouver: University of British Columbia Faculty of Medicine; 2013.

Competing interests: None declared. 